\section{Cellular Physiology and Biochemistry}

Cell Physiol Biochem 2017;44:1024-1037

DOI: $10.1159 / 000485402$

Published online: November 27, 2017

Accepted: October 17, 2017

This article is licensed under the Creative Commons Attribution-NonCommercial-NoDerivatives 4.0 International License (CC BY-NC-ND) (http://www.karger.com/Services/OpenAccessLicense). Usage and distribution for commercial purposes as well as any distribution of modified material requires written permission.

\title{
Stress-Kinase Regulation of TASK-1 and TASK-3
}

\author{
Susanne Rinnéa Aytug K. Kiper ${ }^{a} \quad$ Constanze Schmidt ${ }^{b}$ Beatriz Ortiz-Bonnin ${ }^{a}$ \\ Simone Zwiener ${ }^{a}$ Guiscard Seebohm ${ }^{c}$ Niels Decher ${ }^{a}$
}

anstitute of Physiology and Pathophysiology, Vegetative Physiology, University of Marburg, Marburg, bInstitute of Cardiology, Internal Medicine, Medical Faculty of the University of Heidelberg, Heidelberg, 'Institute of Genetics of Heart Diseases, University of Münster, Münster, Germany

\section{Key Words}

Atrial fibrillation $\bullet \mathrm{K}_{2 \mathrm{P}}$ channels $\bullet$ Obesity $\cdot$ Potassium $\bullet$ PKB $\bullet \mathrm{SGK} \cdot \mathrm{TASK}$

\begin{abstract}
Background/Aims: TASK channels belong to the two-pore-domain potassium $\left(\mathrm{K}_{2 \mathrm{p}}\right)$ channel family. TASK-1 is discussed to contribute to chronic atrial fibrillation (AFib) and has been together with uncoupling protein 1 found as a marker protein of brown adipose tissue (BAT) fat. In addition, TASK-1 was linked in a genome-wide association study to an increased body mass index. A recent study showed that TASK-1 inhibition is causing obesity in mice by a BAT whitening and that these effects are linked to the mineralocorticoid receptor pathway, albeit the mechanism remained elusive. Therefore, we aimed to probe whether $\mathrm{K}_{2 \mathrm{p}}$ channels are regulated by serum- and glucocorticoid-inducible kinases (SGKs) which are known to modify many cellular functions by modulating ion channels. Methods: To this end we used functional co-expression studies and chemiluminescence-assays in Xenopus oocytes, together with fluorescence imaging and quantitative PCR experiments. Results: SGKs and proteinkinase B (PKB) induced a strong, dose- and time-dependent current reduction of TASK-1 and TASK-3. SGK co-expression reduced the surface expression of TASK-1/3, leading to a predominant localization of the channels into late endosomes. The down regulation of TASK-3 channels was abrogated by the dynamin inhibitor dynasore, confirming a role of SGKs in TASK-1/3 channel endocytosis. Conclusion: Stress-mediated changes in SGK expression pattern or activation is likely to alter TASK-1/3 expression at the surface membrane. The observed TASK-1 regulation might contribute to the pathogenesis of chronic AFib and provide a mechanistic link between increased mineralocorticoid levels and TASK-1 reduction, both linked to BAT whitening.
\end{abstract}

\section{Introduction}

The mammalian $\mathrm{K}_{2 \mathrm{P}}$ channel family consists of 15 members of background or leak potassium channels, playing a crucial role in setting the resting membrane potential and thus regulating cellular excitability in many different cell types and tissues. TWIK-related acid- 


\section{Cellular Physiology Cell Physiol Biochem 2017;44:1024-1037 \\ and Biochemistry Published online: November 27, 2017 \begin{tabular}{l|l} 
DOI: 10.1159/000485402 2017 The Author(s). Published by S. Karger AG, Basel \\
www.karger.com/cpb
\end{tabular} \\ Rinné et al.: SGK and PKB Regulation of TASK-1/3}

sensitive $\underline{\mathrm{K}}^{+}$(TASK) channels belonging to the $\mathrm{K}_{2 \mathrm{P}}$ family of potassium channels are relevant for the pathogenesis of many different cardiovascular diseases [1, 2], including pulmonary hypertension [3], obstructive sleep apnea [4] and arrhythmias like atrial fibrillation (AFib) [4-6] or conduction disorders [7, 8].

For instance TASK-1 channels are promising drug targets for the treatment of AFib, as they are upregulated under AFib $[9,10]$ and as these channels have the ability to modulate the human atrial action potential duration under normal and pathological conditions $[5,10]$. As in humans TASK-1 lacks a ventricular expression [5], a pharmacological inhibition of this channel can prolong atrial refractoriness and convert AFib, without causing life threatening ventricular side effects $[4,5]$. On the other hand, the clinical benefit of a TASK-1 inhibition in AFib, in particular the putative side effect of pulmonary hypertension, is currently under debate [10-12]. Noteworthy, TASK-1 currents increased in chronic AFib patients much stronger than expected from transcriptional changes [10], indicating an altered TASK-1 channel regulation during AFib.

TASK-1 has been reported to play a role in glucose-dependent insulin secretion of beta cells [13]. However, TASK-1 might not only be relevant for diabetes but also for obesity, two clinical entities often going hand in hand. Brown adipose tissue (BAT) is thought to protect against obesity, as its activation is causing a state of increased energy expenditure. However, the origin and molecular identity of BAT remained long time elusive. An RNA sequencing and unbiased genome-wide expression analyses approach recently identified TASK-1 (KCNK3) as a marker of BAT [14]. This study confirmed a previous report that the mitochondrial uncoupling protein (UCP1) together with KCNK3 are genetic markers of BAT, as in humans they are differentially expressed in BAT compared to white adipose tissue (WAT) [15]. Note that TASK1-like single channels were previously reported in rat BAT [16], but also another $\mathrm{K}_{2 \mathrm{P}}$ channel, KCNK10, might be relevant in the context of obesity, as this channel plays a role in early stages of adipocyte differentiation [17]. Consistent with the identification of TASK-1 as a marker of BAT, a recent genome-wide association study (GWAS) identified an association of $K C N K 3$ with an increased body mass index [18]. In addition, TASK-1 and UCP1 expression correlated in obese and cold-exposed mice [19] and most strikingly, TASK-1 knock-out mice are overweight because of an increase in WAT mass and BAT whitening [19]. It was concluded that TASK-1 controls the thermogenic activity in BAT, as a decreased oxygen consumption, UCP1 expression and lipolysis was evident under $\beta_{3}$ receptor stimulation. The TASK-1 blocker A293 or an activation of the mineralocorticoid pathway mimicked these effects, suggesting a link between TASK-1 and the mineralocorticoid receptor pathway. This link between TASK-1 and mineralocorticoid receptors was confirmed by the fact that addition of aldosterone to adipocytes of TASK-1 knock-out mice did not induce additional or increased effects [19]. Yet, it remained elusive how the mineralocorticoid pathway is mechanistically coupled to TASK-1 channels. Interestingly, serum- and glucocorticoid-inducible kinase-1 (SGK1) is overexpressed in adipose tissue of subjects with obesity and diabetes [20]. Since SGK kinases are known regulators of ion channels, we started testing whether $\mathrm{K}_{2 \mathrm{P}}$ channels, in particular TASK-1, are regulated by these kinases; aiming to provide a link between the observed changes in SGK expression and the role of mineralocorticoids in brown tissue fat whitening.

SGK1 was initially identified in rat mammary tumor cells, where it was reported as an immediate early gene, with a transcription stimulated by serum and glucocorticoids [2123]. SGKs belong to the family of AGC kinases and all three SGK family members share high amino acid homology to proteinkinase B (PKB) also known as Akt. SGK activity is under transcriptional control by numerous stimuli, including aldosterone [24] or the phosphorylation state. The canonical mechanism of activating all three SGK isoforms is the phosphatidylinositid-3-kinase $\left(\mathrm{PI}_{3} \mathrm{~K}\right)$ pathway [25]. Activation of the pathway induces the production of phospatidyl-inositol- $(3,4,5)$-triphosphate $\left(\mathrm{PIP}_{3}\right)$ by $\mathrm{PI}_{3} \mathrm{~K}$. These lipids serve as plasma membrane docking sites for proteins that harbor pleckstrin-homology domains, including phosphoinositide-dependent kinase 1 (PDK1) resulting in SGK phosphorylation. Additionally, $\mathrm{PIP}_{3}$ leads to mTORC2 activation and SGK phosphorylation [26]. SGKs 
modify a variety of cellular functions either by a direct phosphorylation of ion channels and transporters, by phosphorylation of their regulating proteins or by transcriptional changes [24,27-34]. Strikingly, SGKs preferentially enhance the activity of ion channels and transporters by increasing the expression of the proteins at the plasma membrane [24].

Using a functional co-expression screen, we found a preferential and unusual downregulation of the TASK-1 and TASK-3 channels. All three SGKs, but also the closely related PKB or PDK, which activate SGKs, reduced TASK-1 and TASK-3 current amplitudes by an internalization of the channels into late endosomes. Thus, stress mediated changes in SGK expression levels or altered SGK activation is likely to change TASK-1 and TASK-3 expression at the plasma membrane. This unusual downregulation of TASK-1 by SGKs is likely to contribute to the pathogenesis of chronic AFib and might provide a mechanistic link between increased mineralocorticoid levels and TASK-1 reduction, effects which were recently identified to be linked and to be responsible for brown tissue fat whitening.

\section{Materials and Methods}

\section{Ethical approval}

The investigation conforms to the guide for the Care and Use of laboratory Animals (NIH Publ. 8523). Human tissue samples were obtained from the right atrial (RA) appendages. The study protocol was approved by the ethics committees of the University of Heidelberg (Germany; Medical Faculty Heidelberg, S-017/2013). Written informed consent was obtained from all patients, and the study was conducted in accordance with the Declaration of Helsinki.

\section{Molecular biology}

Human $\mathrm{K}_{2 \mathrm{P}}$ channel constructs (TASK-1, TASK-3, TASK-4, TRESK and TRAAK) and AS160 were cloned into the oocyte expression vector pSGEM. SGK-1, SGK-1 SD, SGK-2, SGK-3, SGK-3 SD, PKB and PDK constructs were used as previously described. For the chemiluminescence assay an hemagglutinin (HA)-epitope (YPYDVPDYA), preceded and followed by a proline-glycine-glycine linker, was inserted in the extracellular P2-M4 loop of rat TASK-1 at amino acid position 214 as previously described [35]. TASK-3 was cloned into pEGFP-C1 vector for imaging experiments.

\section{Oocyte preparation, cRNA synthesis and cRNA injection}

Oocytes were obtained from anesthetized Xenopus laevis frogs and incubated in OR2 solution containing in mM: $\mathrm{NaCl} 82.5, \mathrm{KCl} 2, \mathrm{MgCl}_{2}$ 1, HEPES 5 ( $\mathrm{pH} 7.5$ ) substituted with $2 \mathrm{mg} / \mathrm{ml}$ collagenase II (Sigma) to remove residual connective tissue. Subsequently, oocytes were stored at $18{ }^{\circ} \mathrm{C}$ in ND96 solution supplemented with $50 \mathrm{mg} / \mathrm{l}$ gentamycine, $274 \mathrm{mg} / \mathrm{l}$ sodium pyruvate and $88 \mathrm{mg} / \mathrm{l}$ theophylline. All channels and kinases were subcloned into an oocyte expression vector and cDNA was linearized. cRNA was synthesized with mMESSAGE mMACHINE-Kit (Ambion). The quality of cRNA was tested using gel electrophoresis. Oocytes were each injected with $50 \mathrm{nl}$ of cRNA.

\section{Expression of TASK channels in oocytes}

Stage IV and V oocytes were injected with cRNA. For co-expression experiments $25 \mathrm{ng}$ cRNA of the kinases (SGK1, SGK2, SGK3, PKB, PDK or AS160) were used. In Fig. 3, 50 pg TASK-3 was co-injected with 50 pg (1:1), 500 pg (1:10), 5 ng (1:100) or 25 ng (1:500) SGK-2 cRNA. Standard two-microelectrode voltageclamp (TEVC) recordings were performed at room temperature $\left(20-22^{\circ} \mathrm{C}\right) 1-3$ days after cRNA injection with a TurboTEC 10CD (npi) amplifier and a Digidata 1200 Series (Axon Instruments) as A/D converter. Micropipettes were made from borosilicate glass capillaries GB 150TF-8P (Science Products) and pulled with a DMZ-Universal Puller (Zeitz). Recording pipettes had a resistance of 0.5-1.5 $\mathrm{M} \Omega$ and were filled with $3 \mathrm{M} \mathrm{KCl}$ solution. $\mathrm{ND} 96$ was used as recording solution containing in $\mathrm{mM}: \mathrm{NaCl} 96, \mathrm{KCl} 2, \mathrm{CaCl}_{2} 1.8, \mathrm{MgCl}_{2} 1$, HEPES 5 (pH 7.5).

Chemiluminescence assay

Surface expression of the HA-tagged TASK-1 channel construct was analyzed in Xenopus oocytes. Two days after cRNA injection oocytes were incubated for $30 \mathrm{~min}$ in ND96 solution containing 1\% bovine serum 


\section{Cellular Physiology Cell Physiol Biochem 2017;44:1024-1037 \begin{tabular}{l|l|l} 
and Biochemistry Published 10.1159/000485402 & (c) 2017 The Author(s). Published by S. Karger AG, Basel \\
www.karger.com/cpb
\end{tabular} \\ Rinné et al.: SGK and PKB Regulation of TASK-1/3}

albumin (BSA) at $4^{\circ} \mathrm{C}$ to block non-specific binding of antibodies. Subsequently, oocytes were incubated for 60 min at $4^{\circ} \mathrm{C}$ with $1 \mu \mathrm{g} / \mu \mathrm{l}$ rat monoclonal anti-HA antibody (clone 3F10, Roche) in 1\% BSA/ND96, washed six times at $4^{\circ} \mathrm{C}$ with $1 \% \mathrm{BSA} / \mathrm{ND} 96$, and incubated with $2 \mu \mathrm{g} / \mu \mathrm{l}$ peroxidase-conjugated affinity purified $\mathrm{F}(\mathrm{ab}) 2$ fragment goat anti-rat IgG antibody (Dianova) in 1\% BSA/ND96 for $60 \mathrm{~min}$. Oocytes were washed thoroughly, initially in $1 \% \mathrm{BSA} / \mathrm{ND} 96$ (at $4^{\circ} \mathrm{C}$ for $60 \mathrm{~min}$ ), and then in ND96 without BSA (at $4^{\circ} \mathrm{C}$ for $15 \mathrm{~min}$ ). Individual oocytes were placed in $20 \mu \mathrm{l}$ SuperSignal Elisa Femto solution (Pierce) and chemiluminescence was quantitated in a luminometer (Promega). The luminescence produced by non-injected oocytes was used as a reference signal (negative control).

\section{Fluorescence microscopy}

HeLa and COS-7 cells were grown to approximately $50 \%$ confluence on glass cover slips in $35 \mathrm{~mm}$ Petri dishes (Nunc) using DMEM medium containing $10 \%$ fetal bovine serum (Gibco/Thermo Fisher Scientific) $+1 \%$ penicillin/streptomycin (Gibco/Thermo Fisher Scientific). For live cell imaging cells were grown on $35 \mathrm{~mm}$ glass bottom Petri dishes (Willco). After $24 \mathrm{~h}$, the cells were transfected using jetprime (Polyplus transfection) kit (Peqlab) following manufacture instructions with $0.2 \mu \mathrm{g}$ pEGFP-C1 TASK3 or $1 \mu \mathrm{g}$ pcDNA3.1 SGK1 together with $0.2 \mu \mathrm{g}$ pEGFP-C1 TASK3. The cells were cultured at $37{ }^{\circ} \mathrm{C}$ for $6-36 \mathrm{~h}$ in an incubator supplied with $5 \% \mathrm{CO}_{2} / 95 \% \mathrm{O}_{2}$. Immunofluorescence and live cell imaging was performed utilizing a Zeiss imaging platform comprising an Axio Observer.Z1 microscope equipped with a Plan-Apochromat $60 \times / 1.40$ Oil DIC objective and a standard filter set for EGFP and DSRed (Zeiss 38HE). Digital images were taken with a 12 bit "AxioCam MRm" camera and processed using the AxioVision Software. For immunofluorescence experiments the cells were fixed with $4 \%$ PFA $+4 \%$ saccharose, permeabilized with $0.25 \%(\mathrm{v} / \mathrm{v}$ ) Triton X-100 in PBS and stained with antibodies against late endosomes (CD63 1:200, Santa Cruz Biotechnology) and secondary Alexa 568 antibodies (1:200, Molecular Probes). Inhibition of endocytosis in Hela cells was carried out by incubation with the dynamin inhibitor dynasore ( $80 \mu \mathrm{M}$, Sigma) applied at least 4 hours after transfection.

\section{Quantitative real-time PCR}

Quantitative real-time PCR (RT-qPCR) was performed using the StepOnePlus (Applied Biosystems, Foster City, CA, USA). Total RNA was prepared using TRIzol- Reagent (Invitrogen, Karlsruhe, Germany) according to the manufacturer's instructions. Complementary DNA synthesis was carried out with the Maxima First Strand cDNA Synthesis Kit for RT-qPCR (Thermo Fisher Scientific, Waltham, MA, USA) using $3 \mu \mathrm{g}$ of total RNA. 96 well optical detection plates (Applied Biosystems, Foster City, CA, USA) were then loaded to a total volume of $10 \mu \mathrm{l}$ per well, consisting of $0.5 \mu \mathrm{l}$ cDNA, $5 \mu \mathrm{l}$ TaqMan Fast Universal Master Mix (Applied Biosystems), and 6-carboxyfluorescein (FAM)-labeled TaqMan probes and primers (TaqMan Gene Expression Assays; Applied Biosystems). In addition, pre-designed primers and probes detecting importin 8 (IP08) were used for normalization. All RT-qPCR reactions were performed in triplicate, and control experiments in the absence of cDNA were included. Data are expressed as an average of triplicates. Primers with the following Accession numbers were used: IP08 (Importin 8), Hs00183533_m1; SGK1, Hs00178612_ m1; SGK2, Hs00367639_m1; SGK3, Hs00993639_m1.

\section{Data analyses}

Results are reported as mean \pm SEM ( $n=$ number of oocytes). Statistical differences were evaluated by Student's unpaired t-test. Significance was assumed for $p<0.05$, indicated in the figures by an asterisk $\left(^{*}\right)$, $p<0.01$, by two asterisk $\left(^{* *}\right), \mathrm{p}<0.001$ by three asterisk $\left(^{* * *}\right)$ or by "n.s." for non-significant changes.

\section{Results}

SGKS, PKB and PDK reduce TASK-1 and TASK-3 currents

To probe for a regulation of $\mathrm{K}_{2 \mathrm{P}}$ channels by SGKs, we performed co-expression experiments in Xenopus laevis oocytes (Fig. 1). Here, co-expression of SGK2 did not affect TASK-4, TRESK and TRAAK currents amplitudes, while it caused a pronounced reduction of currents encoded by the acid-sensitive $\mathrm{K}_{2 \mathrm{P}}$ channels TASK-1 and TASK-3 (Fig. 1A, B). To test for a putative inhibition of TASK-1 and TASK-3 currents by the other SGK isoforms and 

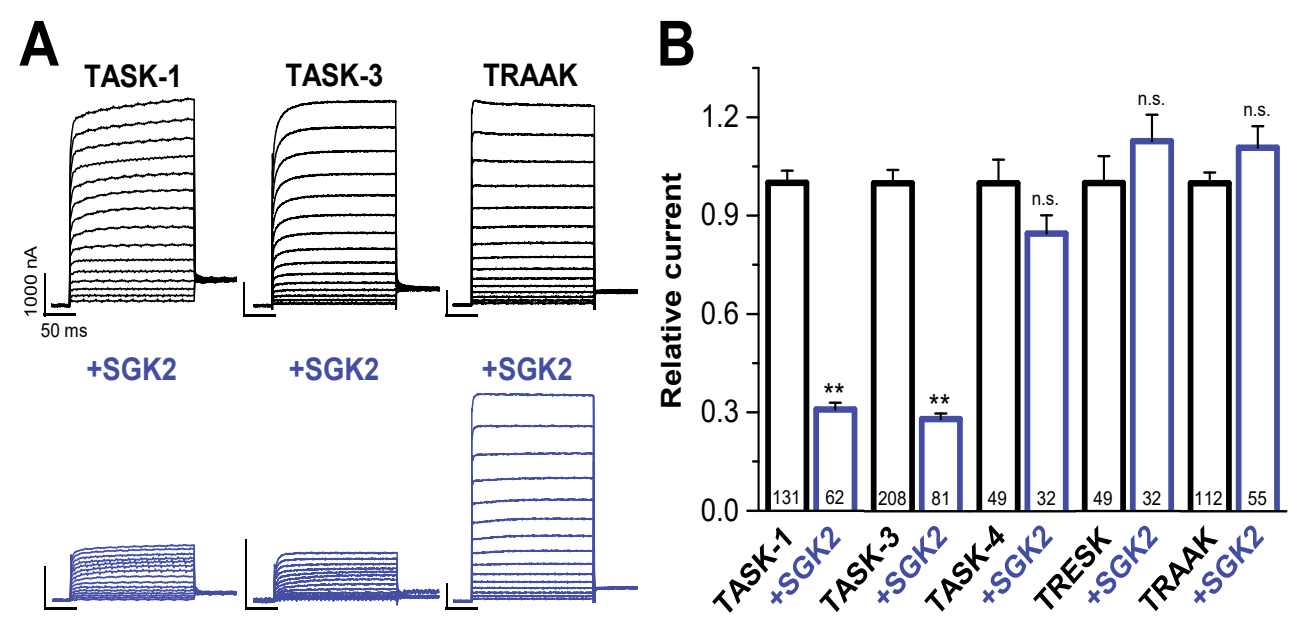

Fig. 1. SGK2 reduces the current amplitudes of TASK-1 and TASK-3 channels. (A), Representative current voltage relationship measurements in Xenopus oocytes injected with cRNA of TASK-1 (1.5 ng/oocyte), TASK-3 (50 pg/oocyte) or TRAAK (2.5 ng/oocyte) (upper panel) or co-injected with SGK2 cRNA (25 ng/ oocyte) (lower panel). Voltage was stepped from a holding potential of $-80 \mathrm{mV}$ to potentials ranging from $-100 \mathrm{mV}$ to $+60 \mathrm{mV}$ in $20 \mathrm{mV}$ increments. Voltage step duration was $200 \mathrm{~ms}$ and voltage steps were repeated every $2 \mathrm{~s}$. Test pulses were followed by a step to $-40 \mathrm{mV}$. (B), Normalized current amplitudes at $+40 \mathrm{mV}$ of different $\mathrm{K}_{2 \mathrm{P}}$ channels injected alone or co-injected with SGK2. Xenopus oocytes were injected with TASK-4 (25 ng/oocyte), TRESK (2.5 ng/oocyte) or co-injected with SGK2 cRNA (25 ng/oocyte) and recorded $48 \mathrm{~h}$ after injection. The numbers of experiments are indicated within the bar graph.

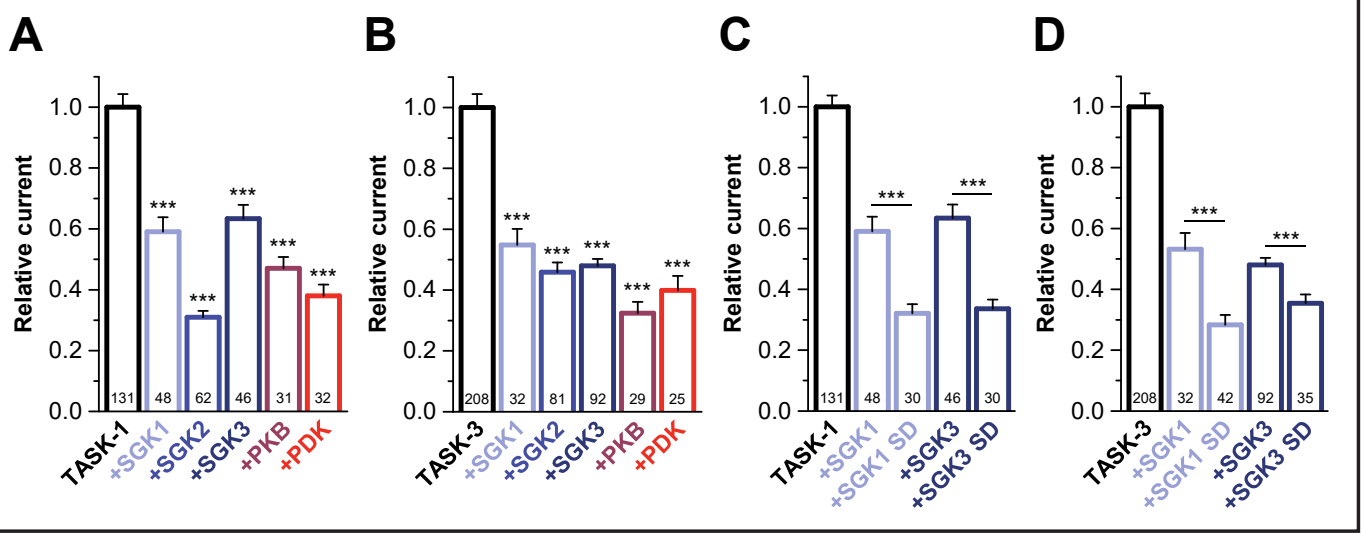

Fig. 2. SGKs, PKB and PDK reduce TASK-1 and TASK-3 current amplitudes. (A), The effect of SGK1, SGK2, SGK3, PKB and PDK (25 ng/oocyte) on the mean current amplitude of TASK-1 (1.5 ng/oocyte) or (B),

TASK-3 (50 pg/oocyte) at $+40 \mathrm{mV}$, recorded in Xenopus oocytes $48 \mathrm{~h}$ after cRNA injection. (C), A dominant active mutant of SGK1 (SGK1 SD) or SGK3 (SGK3 SD) was co-injected with TASK-1 or with (D), TASK-3 in Xenopus oocytes and mean current amplitudes at $+40 \mathrm{mV}$ were analyzed $48 \mathrm{~h}$ after cRNA injection. The numbers of experiments are indicated within the bar graph.

by PKB, sharing high homology to SGK2, these kinases were individually co-expressed with TASK-1 and TASK-3 in Xenopus oocytes. All kinases shared the ability to strongly reduce the current amplitudes of both, TASK-1 (Fig. 2A) and TASK-3 (Fig. 2B), albeit with different efficiencies. For both TASK channels, SGK2 provoked the most pronounced current reduction of all SGK isoforms tested. PDKs are known to phosphorylate and thereby activate SGKs. PDK was co-injected with TASK-1 or TASK-3 (Fig. 2A, B). PDK causes a current reduction of both channels, most probably indirectly via an activation of endogenous SGKs since TASK-1/3 


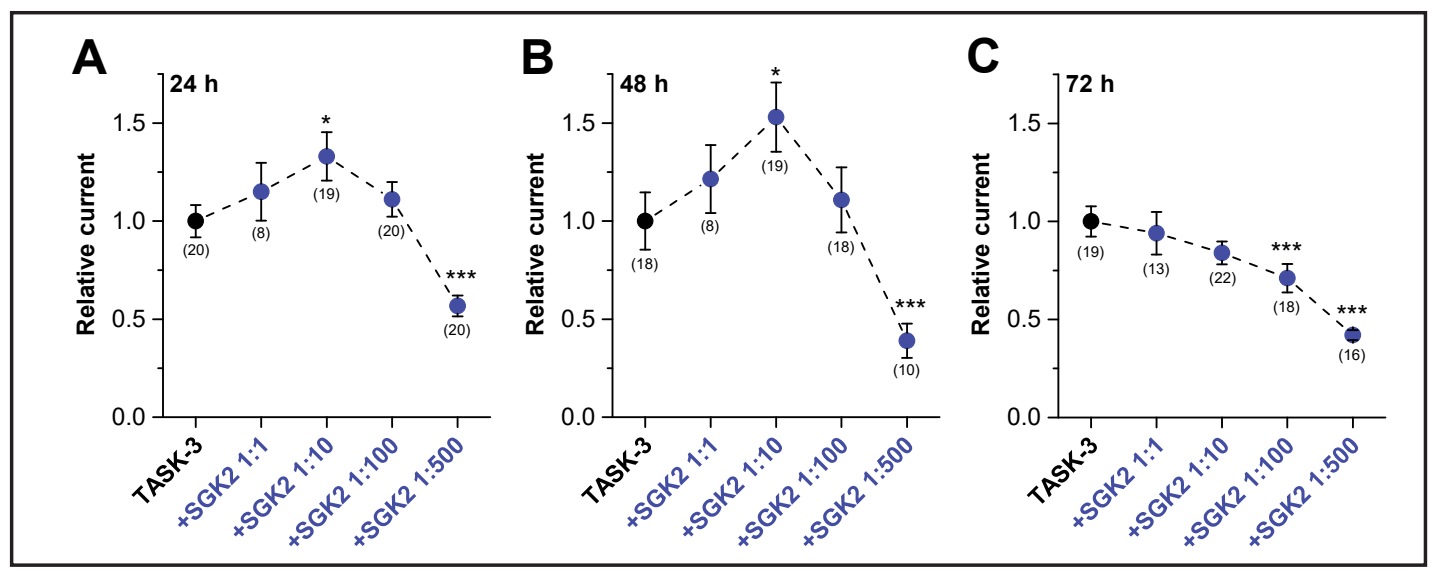

FIG. 3. SGK2 causes a time- and dose-dependent reduction of TASK- 3 current amplitudes. TASK- 3 cRNA (50 pg) was injected in Xenopus oocytes and the indicated amounts of SGK2 cRNA were co-injected (50 pg (1:1), $500 \mathrm{pg}$ (1:10), $5 \mathrm{ng}$ (1:100) or $25 \mathrm{ng}$ (1:500)). Currents at $+40 \mathrm{mV}$ were measured (A), $24 \mathrm{~h},(\mathrm{~B}), 48 \mathrm{~h}$ or (C), $72 \mathrm{~h}$ after injection. The numbers of experiments are indicated underneath each circle.

do not contain PDK phosphorylation consensus sites. In addition, we co-expressed TASK-1 or TASK-3 with dominant active SGK constructs, SGK1 ${ }^{\text {S422D }}$ (SGK1 SD) and SGK3 ${ }^{\text {S356D }}$ (SGK3 SD), mimicking SGK phosphorylation in its C-terminus, thereby activating the kinases. The co-expression of both, SGK1 SD and SGK3 SD, led to an even more pronounced reduction of TASK-1 (Fig. 2C) as well as for TASK-3 (Fig. 2D).

\section{SGK-2 effect on TASK-3 is time and dose dependent}

SGK kinases almost exclusively increase the surface expression of many ion channels and transporters, albeit by distinct mechanism. Surprisingly, in this study we noticed a current reduction of the $\mathrm{K}_{2 \mathrm{P}}$ channels TASK- 1 and TASK3 via SGK kinases, PKB and PDK. Hence, we studied a potential dose and time dependence of the effect. For this purpose different cRNA ratios $(1: 1,1: 10,1: 100$ and 1:500) of TASK-3 and SGK2 were co-expressed in oocytes and current amplitudes were measured at different time points after injection $(24 \mathrm{~h}, 48 \mathrm{~h}$ and 72 h) (Fig. 3). Here, small amounts of SGK2 (1:1 to $1: 10$ ratio of channel to kinase) led to a current increase after 24 and $48 \mathrm{~h}$, whereas the presence of more SGK2, similar as utilized in the initial search for modulated $\mathrm{K}_{2 \mathrm{P}}$ channels, or recordings at later time points $(72 \mathrm{~h})$, led to a current reduction. After $72 \mathrm{~h}$ all ratios tested resulted in a TASK-3 current reduction. In conclusion, TASK-3 down regulation seemed to be concentration and time dependent.

SGK reduces the surface expression of TASK-1/3 channels

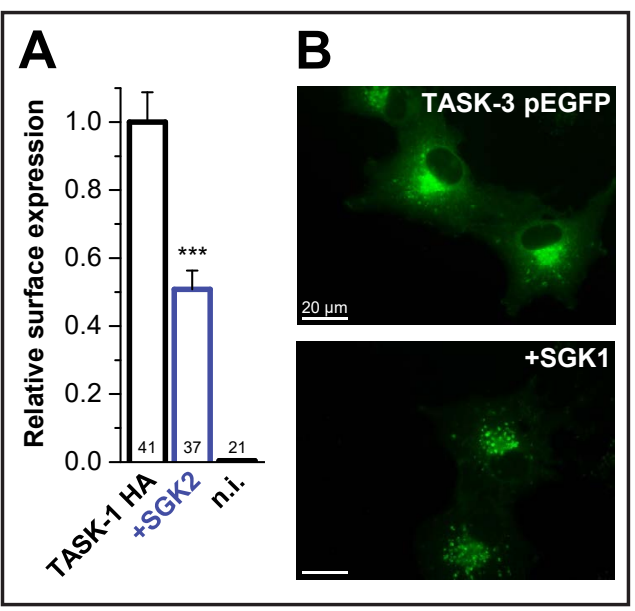

Fig. 4. SGK2 reduces the surface expression of TASK-1. (A), Luminometric quantification of the surface expression of extracellularly HA-tagged TASK-1 channels (TASK- ${ }^{\text {HA }}$ ) in Xenopus oocytes. Relative surface expression $( \pm$ SEM) after coinjection of SGK2 was normalized to TASK- ${ }^{\text {HA. }}$. n.i.: non-injected oocytes. The numbers of experiments are indicated within the bar graph. (B), Live cell imaging in COS-7 cells $24 \mathrm{~h}$ after transfection of TASK-3 pEGFP alone (upper panel) or together with SGK1. 


\section{Cellular Physiology Cell Physiol Biochem 2017;44:1024-1037

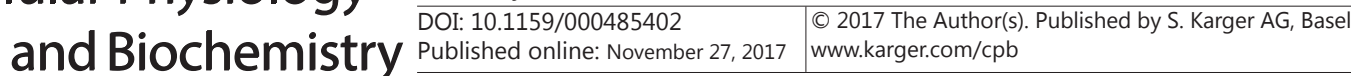 Rinné et al.: SGK and PKB Regulation of TASK-1/3}
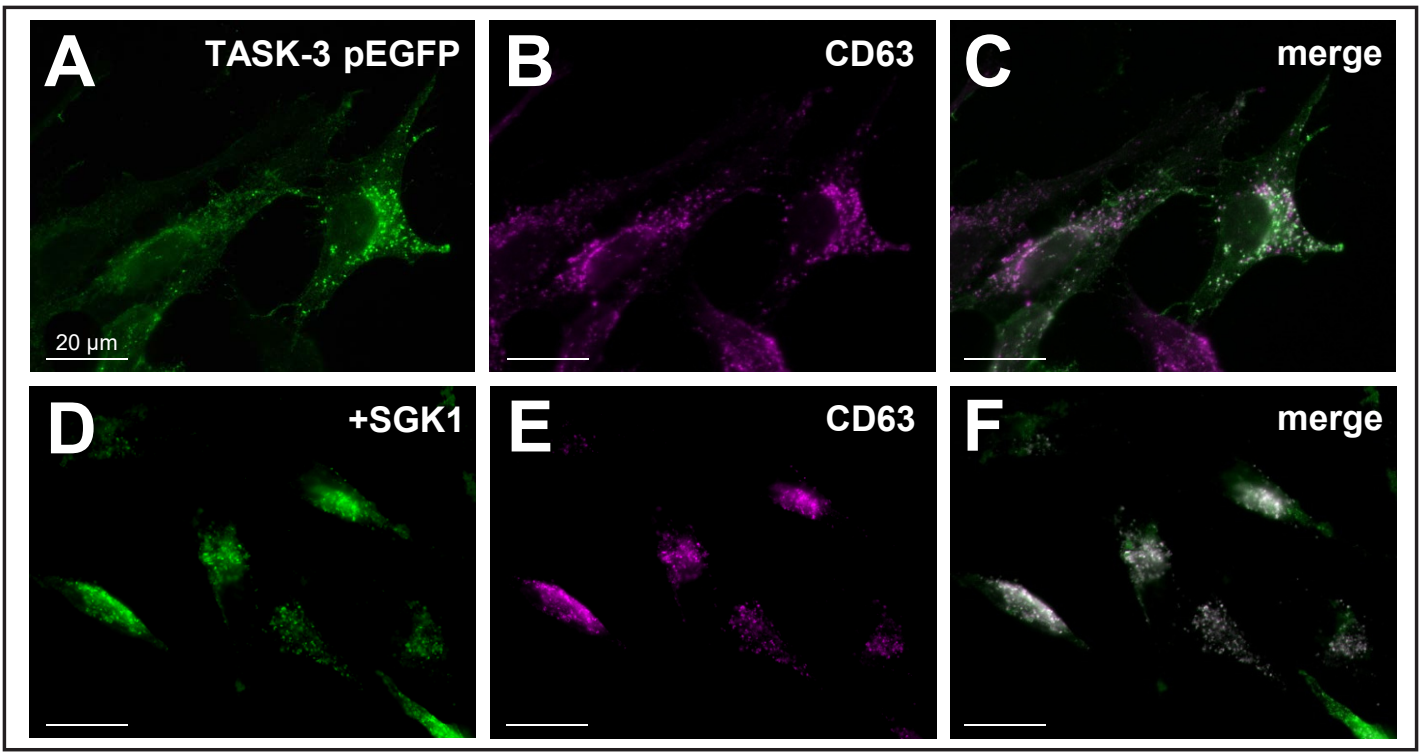

Fig. 5. SGK1 overexpression results in localization of TASK-3 in a late endosome-like compartment. HeLa cells were transfected with (A-C), TASK-3 pEGFP or (D-F), TASK-3 pEGFP and SGK1. $24 \mathrm{~h}$ after transfection cells were fixed and stained with the late endosomal marker CD63 (magenta). (C), Merge of images (A) and (B). (F), merge of images (D) and (E).

extracellular HA epitope was introduced in the second extracellular pore loop of TASK-1. Performing an ELISA based chemiluminescence assay, co-expression of SGK-2 (1:500) caused a reduction of the TASK-1 surface expression (Fig. 4A). In addition, we performed live cell imaging in COS-7 cells transfected with TASK-3 pEGFP alone or together with SGK-1. After $24 \mathrm{~h}$, in the presence of SGK-1, TASK-3 was hardly detected at the plasma membrane and a dotted, presumably endosomal pattern was observed (Fig. 4B). Thus, SGKs may regulate trafficking of TASK-3, leading to an increased fraction of intracellular channel protein.

\section{TASK-3 co-localizes with the late endosome marker CD63}

To gain further insights into the intracellular localization of TASK-3 in the presence of SGK1, we transfected HeLa cells with TASK-3 pEGFP alone or together with SGK1. Cells were fixed $24 \mathrm{~h}$ after transfection and stained with the late endosomal marker CD63 (Fig. 5). These experiments showed that SGK1 co-expression leads to a more pronounced endosomal TASK-3 localization, indicated by the co-localization with CD63 (Fig. 5F). Furthermore, time line experiments in HeLa cells showed that 12 hours after transfection TASK-3 is already reaching the surface membrane, while TASK-3 co-expressed with SGK1 was still predominantly localized in cytoplasmatic vesicles (for all online suppl. material, see www. karger.com/doi/10.1159/000485402, Suppl. Fig. 1B, F). After 24h of incubation TASK-3 is strongly expressed at the plasma membrane, while TASK-3 co-expressed with SGK1 showed a clearly reduced surface expression and many vesicles around the nuclei (see online suppl. material, Suppl. Fig. 1C, G). After 36 hours TASK-3 still predominantly localized to the plasma membrane, while co-expression with SGK1 apparently retrieved the channels to vesicles in the perinuclear area (see online suppl. material, Suppl. Fig. 1D, H).

TASK-3, in the presence of SGK2, is internalized via a Rab4- and Rab5-dependent pathway

We observed that co-expression of TASK-1 and TASK-3 with SGKs leads to a rapid current reduction, especially using higher concentrations of SGKs (Fig. 3A). Thus, we speculated that the channels, in order to reach the late endosomal compartment, are quickly internalized by an early endosomal pathway. To challenge this question, TASK-3 together with SGK2 was co-expressed with either a wild-type Rab or its dominant-negative construct (Fig. 6A, B). Inhibition of early endocytosis with dominant-negative Rab4 or dominant-negative Rab5

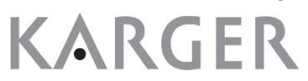


Fig. 6. Endocytosis of TASK-3 by SGK2 is mediated by a Rab4- and Rab5-dependent pathway. TASK-3 together with SGK2 was coexpressed with either wild-type or dominant-negative Rab constructs in Xenopus oocytes and current amplitudes were analyzed $48 \mathrm{~h}$ after injection. (A), representative current traces of TASK-3 together with SGK2 in the presence of wild-type or dominant-negative Rab proteins. (B), Respective analyses of the changes in current amplitudes. The numbers of experiments are indicated within the bar graph.
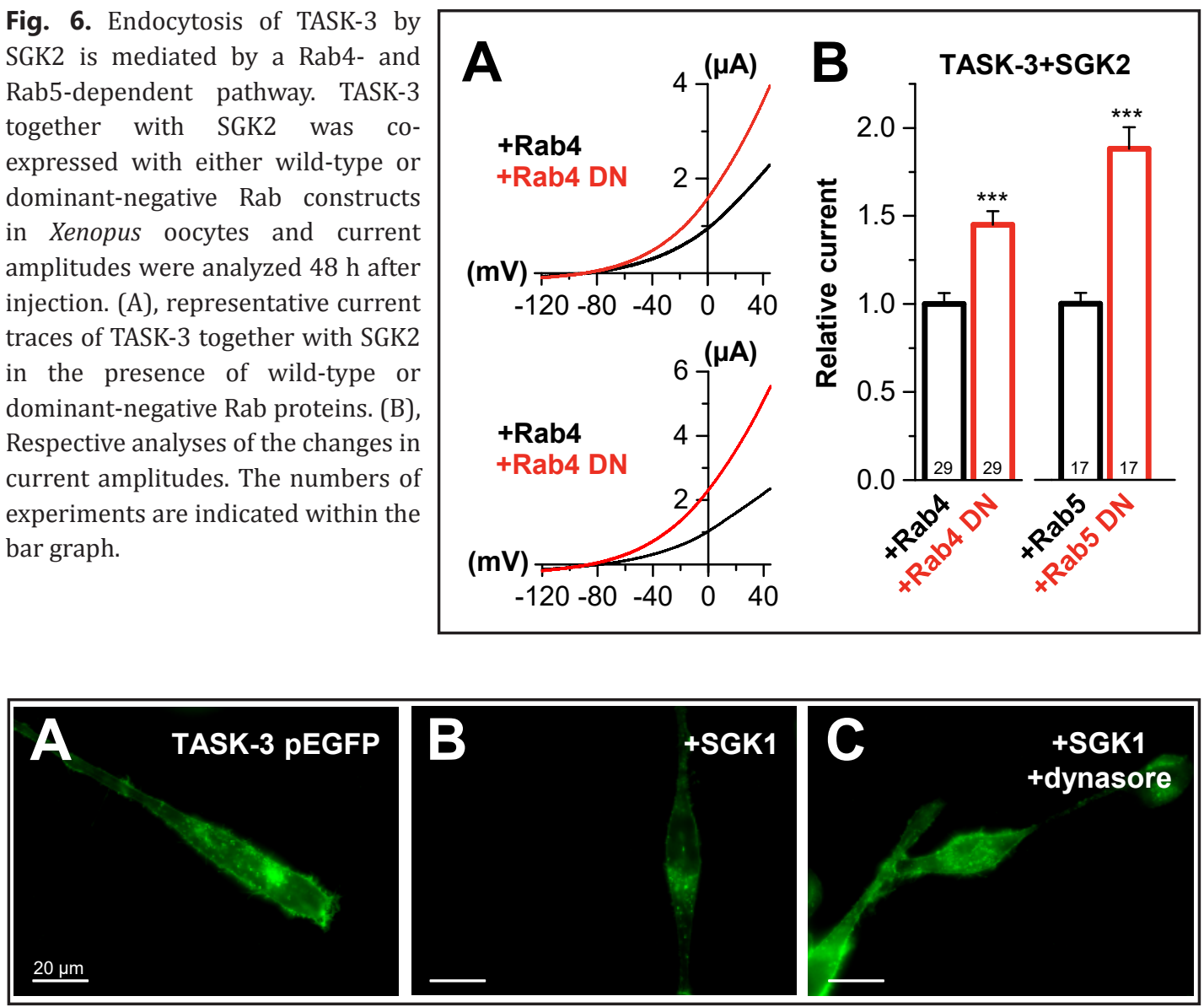

Fig. 7. SGK1 leads to a clathrin-dependent endocytosis of TASK-3. Live cell imaging of HeLa cells $24 \mathrm{~h}$ after transfection with (A), TASK-3 pEGFP, (B), TASK-3 pEGFP and SGK1, (C), TASK-3 pEGFP and SGK1 in the presence of $80 \mu \mathrm{M}$ of the dynamin-inhibitor dynasore.

increases TASK-3 current amplitudes (Fig. 6A, B). This data indicates that TASK-3 is in the presence of SGK2 endocytosed via a Rab4 and Rab5 dependent early endocytosis pathway.

The SGK mediated reduction of TASK-3 surface expression is antagonized by blocking clathrin-mediated endocytosis

Dynasore blocks dynamin and is a specific and highly effective blocker of clathrinmediated endocytosis. In this study, we applied dynasore $(80 \mu \mathrm{M})$ after transfecting HeLa cells with TASK-3 alone or together with SGK1. Similar as described above (see online suppl. material, Suppl. Fig. 1C, G), 24 hours after transfecting TASK-3 together with SGK1, the channel was located at the surface membrane, albeit with a reduced efficiency (Fig. 7A, B), which also becomes evident by the less pronounced formation of filopodia (Fig. 7B and see online suppl. material, Suppl. Fig. 1G). Strikingly, when cells co-transfected with TASK-3 and SGK1 in the presence of dynasore, we observed a massive increase in fluorescence at the plasma membrane and a pronounced formation of filopodia, confirming that the current reduction of TASK-3 by SGKs is mediated by endocytosis.

Putative interaction partners mediating the indirect effect of SGKs and PKB on TASK-1/3?

Since TASK-1 and TASK-3 do not contain consensus motifs for SGKor PKB phosphorylation, the observed TASK channel regulation must be indirect in nature. Several mechanisms for an indirect ion channel regulation via SGKs are described including the involvement of Nedd4-2, NHERF2, PIKfyve, AS160 or 14-3-3. Since TASK-1 and TASK-3 surface expression is 


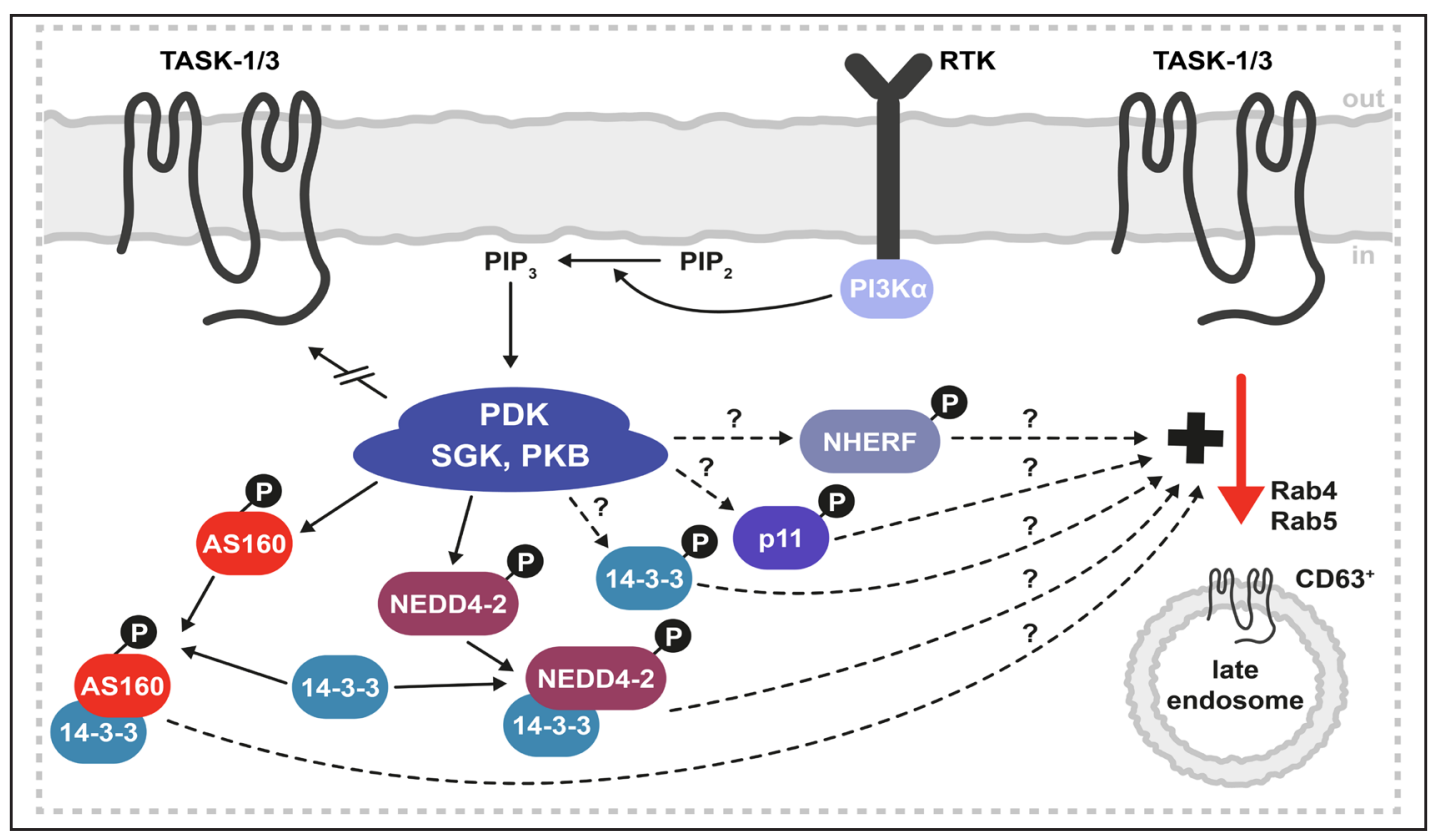

Fig. 8. Putative interaction partners mediating the indirect effect of SGKs and PKB on TASK- $1 / 3$. The cartoon illustrates that the $\mathrm{PI}_{3}$-kinase-pathway should regulate TASK-1/3 channels via a PDK/SGK activation. Illustrated is in addition that this indirect pathway might involve a variety of different proteins. RTK, receptor tyrosine kinase; NHERF, $\mathrm{Na}^{+} / \mathrm{H}^{+}$exchanger regulatory factor; NEDD4-2, neural precursor cell-expressed developmentally downregulated gene 4-2; AS160, Akt Substrate with 160 kilodalton; PI3K $\alpha$, Phosphoinositide 3-kinase $\alpha$.

regulated in a 14-3-3 dependent manner, we tested whether AS160 might be involved in the

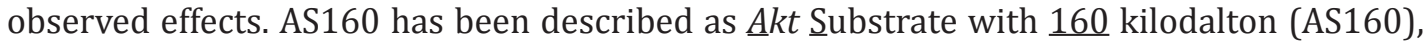
as it is phosphorylated by PKB. Phosphorylation of AS160 by PKB $(A k t)$ or SGKs will lead to a binding of 14-3-3 which might interfere with an efficient TASK-1/3 surface expression. Coinjection of AS160 with TASK-3 resulted in a similar current decrease as the co-injection of small amounts of SGK2 (see online suppl. material, Suppl. Fig. 2). Moreover, co-expression of both, small amounts of SGK2 and AS160, led to an even more pronounced TASK-3 current reduction. However, 14-3-3 is known to regulate forward trafficking of TASK-1 and TASK-3 and not channel endocytosis. Thus, despite some evidence for the involvement of AS160 in TASK channel regulation, the complete pathway and mediators of the indirect TASK channel modulation by SGKs currently remain elusive (Fig. 8).

Decreased expression of SGK1 and SGK2 in atrial cardiomyocytes of patients with chronic AF might contribute to increased TASK-1 currents

TASK-1 is a promising target for the treatment and prevention of AFib. Previously an up-regulation of TASK-1 was observed under chronic AFib that might contribute to the pathogenesis of this common arrhythmia. Surprisingly, the TASK-1 currents recorded from atrial cardiomyocytes from patients with chronic AFib were increased more than expected by the transcriptional changes in mRNA and the resulting protein levels. This effect was not present in patients with paroxysmal AFib. Using quantitative PCR experiments we analyzed changes in the mRNA expression of SGK1-3 in atrial cardiomyocytes of control probands compared to patients with paroxysmal and chronic AFib (Fig. 9 and see online suppl. material, Suppl. Fig. 3). In atrial cardiomyocytes of patients with chronic AFib we observed decreased expression levels of SGK1 and SGK2 which were not present in patients with paroxysmal AFib. The reduced expression levels of SGK1 and SGK2 might contribute to the pronounced increase in TASK-1 currents typical for chronic AFib, as reduced SGK levels are likely to increase the surface expression of TASK-1 and TASK-3. 
Fig. 9. Decreased expression of SGK1 and SGK2 in atrial cardiomyocytes of patients with chronic AFib. Quantitative PCR experiments analyzing changes in SGK expression in patients with chronic atrial fibrillation (cAFib). mRNA expression $( \pm$ S.E.M.) normalized to IP08 for (A), SGK1 (B), SGK2 and (C), SGK3. Two to four triplicates were analyzed and total numbers of experiments are indicated within the bar graphs.

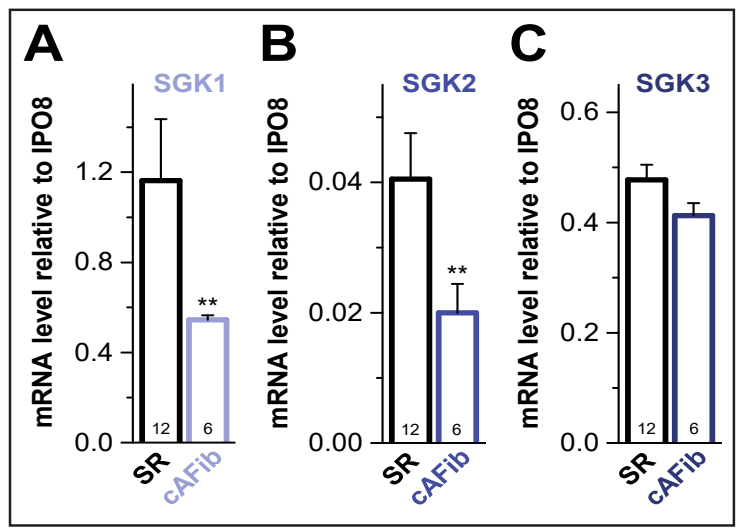

\section{Discussion}

We have observed that SGKs cause a strong reduction of TASK-1 and TASK-3 currents, by a reduced number of channels at the plasma membrane, as shown with voltage clamp recordings in combination with an ELISA-based chemiluminescence assay. All SGK isoforms as well as PKB shared the ability to reduce the current amplitudes of both TASK-1 and TASK-3. Fluorescence imaging experiments revealed that in the presence of SGK1, TASK3 was only weakly expressed at the plasma membrane and that SGK1 co-expression leads to a predominant localization of TASK-3 channels in an endosome-like compartment. The down regulation of TASK-3 was abolished by the dynamin inhibitor dynasore, suggesting a role of SGK in TASK channel endocytosis. TASK-1 and TASK-3 have no consensus sequence predicting a SGK phosphorylation site. Thus, an indirect modulation by SGKs is likely and several mechanisms for such an indirect regulation were previously described [36-44]. Substrates mediating effects by SGKs include for example PIKfyve, AS160, Nedd4-2, NHERF2 or 14-3-3 [45-47]. Interestingly, TASK channels are regulated via 14-3-3 enhancing channel surface expression. Since besides TASK-1 and TASK-3 none of the tested $\mathrm{K}_{2 \mathrm{P}}$ channels is sensitive to SGKs and 14-3-3 [35, 48, 49], it may be possible that the SGK effects are mediated by 14-3-3 and the Rab protein regulator AS160. In the case of the epithelial sodium channel, $\mathrm{ENaC}$, Liang et al. [47] showed that an aldosterone induced phosphorylation of AS160 at its SGK1 phosphorylation sites, evoked a binding of AS160 to the steroid-induced 143-3 isoforms $\beta$ and $\varepsilon$ [47]. This interaction of AS160 with 14-3-3 $\beta$ and $\varepsilon$ was blocked by mutations at the SGK1 phosphorylation sites, suppressing the ability of AS160 to augment aldosterone action on ENaC [47]. In our experiments AS160 co-expression led to reduced TASK-3 currents which was even more pronounced in the presence of SGK2. Thus, AS160 phosphorylation by SGKs may evoke 14-3-3 binding or scavenging 14-3-3 which is however required for TASK forward transport. On the other hand our experiments clearly identified an increased endocytosis of TASK channels and do not point towards an altered forward transport. Thus, the precise mechanism of the indirect regulation of TASK channels and the substrates mediating these SGK effects currently remain elusive and include a plethora of putative pathways (Fig. 8). Since SGKs almost exclusively increase the surface expression of ion channels and transporters, the effect of an increased endocytosis of TASK-1 and TASK-3 channels might obey an unusual or not yet identified novel pathway. Thus, identifying the precise trafficking mechanisms and partners will require independent and intensive future studies.

During AFib KCNK3 (TASK-1) is transcriptionally upregulated [9, 10], an effect which we have also observed in our hands (not published). In a study by Schmidt et al., TASK-1 is upregulated in atrial cardiomyoyctes of patients with chronic AFib by a factor of 1.6 on mRNA and protein level [10]. However, the TASK-1 currents recorded from atrial cardiomyocytes of these patients increased much stronger (3-fold), resulting in shortened action potentials in patients with chronic AFib. As the TASK-1 currents increased much stronger than expected by the changes on mRNA and protein level it suggested an altered regulation of TASK-1 


\section{Cellular Physiology \begin{tabular}{|l|l|l|l|}
\hline DOI: 10.1159/000485402 & $\begin{array}{l}\text { C) } 2017 \text { The Author(s). Published by S. Karger AG, Basel } \\
\text { www.karger.com/cpb }\end{array}$ \\
\hline
\end{tabular}

Fig. 10. Putative role of TASK-1 modulation by SGKs in AFib and BAT whitening. (A), The cartoon illustrates that the TASK-1 current increase in chronic AFib might occur in a synergistic manner by a transcriptional upregulation and by increasing the number of channels at the surface membrane, due to reduced SGK1 and SGK2 expression levels. (B), The cartoon illustrates that a pharmacological and a genetic block of TASK-1 leads to a brown tissue fat whitening

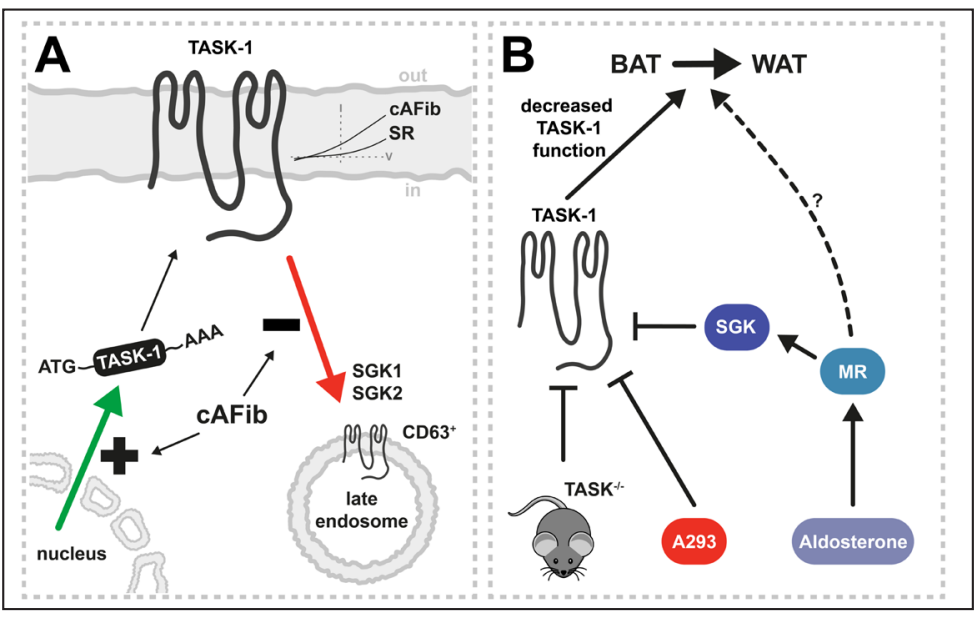
which is linked to an activation of the mineralocorticoid receptor pathway, albeit with a yet unclear mechanism (?). We propose that the mechanistic link between mineralocorticoid receptor pathway stimulation and TASK-1 inhibition in brown tissue fat whitening is reflected by the SGK dependent inhibition of TASK-1.

surface expression or gating during AFib. The transcriptional downregulation of SGK1 and SGK2 in the atria of patients with chronic AFib that we have found in our current study may explain the unexpectedly pronounced increase in TASK-1 current amplitudes during AFib (Fig. 10A). This effect however might be an important factor contributing to the electrical remodeling and chronification of AFib by increased TASK-1 currents and enhanced rates of repolarization.

TASK-1 knock-out mice are overweight due to an increase in WAT mass and a BAT whitening [19]. It was found that TASK-1 controls the thermogenic activity in BAT and that TASK-1 blockers or mineralocorticoids mimic these effects. Although the link between TASK-1 and mineralocorticoid receptors was impressively elaborated and confirmed, i.e. by the fact that aldosterone cannot induce effects in adipocytes of the TASK-1 knock-out mice [19], the mechanism of this functional coupling remained elusive. According to our new data, increased mineralocorticoid levels should stimulate SGKs in adipocytes leading to a reduction of functional TASK- 1 currents at the plasma membrane, similar as in the genetic mouse model or by A293, providing the missing mechanistic link for the BAT whitening observed by decreasing TASK-1 expression or increasing mineralocorticoid levels (Fig. 10B). This hypothesis is further supported by the fact that SGK1 is overexpressed in adipose tissue of subjects with obesity and diabetes [20].

Patients with type 2 diabetes have increased insulin levels, resulting in an upregulation of the $\mathrm{PI}_{3}$-kinase-pathway which is thought to cause cardiac repolarization abnormalities and arrhythmias [50]. An upregulation of the $\mathrm{PI}_{3}$-kinase-pathway will also result in an activation of SGKs and might cause a reduction of TASK channels. Therefore, these effects might contribute to cardiac arrhythmias and the obesity observed in diabetes. For diabetes this would reflect a circulus vitiosus, as obesity is involved in the development of the hyperinsulinism.

Summarizing we hypothesize that stress-mediated changes in SGK expression pattern or activation is likely to alter TASK-1 and TASK-3 expression at the plasma membrane. The down regulation of TASK-1 by SGKs is likely to contribute to the pathogenesis of chronic AFib and provides a mechanistic link between increased mineralocorticoid levels and the TASK-1 reduction responsible for brown tissue fat whitening. As TASK-1 channels appear to be involved in the pathogenesis of many diseases, including obstructive sleep apnea and pulmonary hypertension, it is promising to study the stress-kinase dependent regulation of these channels in different pathophysiological settings. 


\section{Cellular Physiology Cell Physiol Biochem 2017;44:1024-1037 \begin{tabular}{l|l|l} 
and Biochemistry POI: 10.1159/000485402 & (c) 2017 The Author(s). Published by S. Karger AG, Basel \\
wwwkarger.com/cpb
\end{tabular} \\ Rinné et al.: SGK and PKB Regulation of TASK-1/3}

\section{Acknowledgements}

We thank Oxana Nowak for excellent technical support and Thomas Dräbing for voltage-clamp recordings. This work was supported by Kempkes Stiftung (grant 12/08 to N.D.) and by grants of the Deutsche Forschungsgemeinschaft DE-1482/2-1 and DE1482/3-1 to N.D., in part by research grants from the University of Heidelberg, Faculty of Medicine (Rahel Goitein-Straus Scholarship and Olympia-Morata Scholarship to C.S.), from the DZHK (German Center for Cardiovascular Research; Excellence Grant to C.S.), from the German Heart Foundation/German Foundation of Heart Research (F/41/15 to C.S.), from the Deutsche Forschungsgemeinschaft (German Research Foundation; SCHM 3358/1-1 to C.S.), the Universitätsklinikum Gießen and Marburg (UKGM) to S.R. and the Anneliese Pohl Stiftung to S.R..

\section{Disclosure Statement}

None declared.

\section{References}

$\checkmark 1$ Decher N, Kiper AK, Rolfes C, Schulze-Bahr E, Rinné S: The role of acid-sensitive two-pore domain potassium channels in cardiac electrophysiology: focus on arrhythmias. Pflügers Arch 2015;467:10551067.

2 Wiedmann F, Schmidt C, Lugenbiel P, Staudacher I, Rahm AK, Seyler C, Schweizer PA, Katus HA, Thomas D: Therapeutic targeting of two-pore-domain potassium $\mathrm{K}_{2 \mathrm{P}}$ channels in the cardiovascular system. Clin Sci (Lond) 2016;130:643-650.

3 Ma L, Roman-Campos D, Austin ED, Eyries M, Sampson KS, Soubrier F, Germain M, Tregouet DA, Borczuk A, Rosenzweig EB, Girerd B, Montani D, Humbert M, Loyd JE, Kass RS, Chung WK: A novel channelopathy in pulmonary arterial hypertension. N Engl J Med 2013;369:351-361.

4 Kiper AK, Rinné S, Rolfes C, Ramirez D, Seebohm G, Netter MF, Gonzalez W, Decher N: Kv1.5 blockers preferentially inhibit TASK-1 channels: TASK-1 as a target against atrial fibrillation and obstructive sleep apnea? Pflügers Arch 2015;467:1081-1090.

5 Limberg SH, Netter MF, Rolfes C, Rinné S, Schlichthörl G, Zuzarte M, Vassiliou T, Moosdorf R, Wulf H, Daut J, Sachse FB, Decher N: TASK-1 channels may modulate action potential duration of human atrial cardiomyocytes. Cell Physiol Biochem 2011;28:613-624.

6 Liang B, Soka M, Christensen AH, Olesen MS, Larsen AP, Knop FK, Wang F, Nielsen JB, Andersen MN, Humphreys D, Mann SA, Huttner IG, Vandenberg JI, Svendsen JH, Haunso S, Preiss T, Seebohm G, Olesen SP, Schmitt N, Fatkin D: Genetic variation in the two-pore domain potassium channel, TASK-1, may contribute to an atrial substrate for arrhythmogenesis. J Mol Cell Cardiol 2014;67:69-76.

-7 Decher N, Wemhöner K, Rinné S, Netter MF, Zuzarte M, Aller MI, Kaufmann SG, Li XT, Meuth SG, Daut J, Sachse FB, Maier SK: Knock-out of the potassium channel TASK-1 leads to a prolonged QT interval and a disturbed QRS complex. Cell Physiol Biochem 2011;28:77-86.

-8 Friedrich C, Rinné S, Zumhagen S, Kiper AK, Silbernagel N, Netter MF, Stallmeyer B, Schulze-Bahr E, Decher $\mathrm{N}$ : Gain-of-function mutation in TASK-4 channels and severe cardiac conduction disorder. EMBO Mol Med 2014;6:937-951.

9 Barth AS, Merk S, Arnoldi E, Zwermann L, Kloos P, Gebauer M, Steinmeyer K, Bleich M, Kääb S, Hinterseer M, Kartmann H, Kreuzer E, Dugas M, Steinbeck G, Nabauer M: Reprogramming of the human atrial transcriptome in permanent atrial fibrillation: expression of a ventricular-like genomic signature. Circ Res 2005;96:1022-1029.

-10 Schmidt C, Wiedmann F, Voigt N, Zhou XB, Heijman J, Lang S, Albert V, Kallenberger S, Ruhparwar A, Szabo G, Kallenbach K, Karck M, Borggrefe M, Biliczki P, Ehrlich JR, Baczko I, Lugenbiel P, Schweizer PA, Donner $\mathrm{BC}$, Katus HA, Dobrev D, Thomas D: Upregulation of $\mathrm{K}_{2 \mathrm{P}} 3.1 \mathrm{~K}^{+}$Current Causes Action Potential Shortening in Patients With Chronic Atrial Fibrillation. Circulation 2015;132:82-92.

11 Olschewski A, Chandran N, Olschewski H: Letter by Olschewski et al. Regarding Article, "Upregulation 


\section{Cellular Physiology Cell Physiol Biochem 2017;44:1024-1037 \begin{tabular}{l|l|l} 
and Biochemistry Published online: November 27, 2017 & $\begin{array}{l}\text { (c) } 2017 \text { The Author(s). Published by S. Karger AG, Basel } \\
\text { www.karger.com/cpb }\end{array}$
\end{tabular} \\ Rinné et al.: SGK and PKB Regulation of TASK-1/3}

of $\mathrm{K}_{2 \mathrm{P}} 3.1 \mathrm{~K}^{+}$Current Causes Action Potential Shortening in Patients With Chronic Atrial Fibrillation”. Circulation 2016;133:e439.

-12 Schmidt C, Wiedmann F, Voigt N, Zhou XB, Heijman J, Lang S, Albert V, Kallenberger S, Ruhparwar A, Szabo G, Kallenbach K, Karck M, Borggrefe M, Biliczki P, Ehrlich JR, Baczko I, Lugenbiel P, Schweizer PA, Donner BC, Katus HA, Dobrev D, Thomas D: Response to Letter Regarding Article, "Upregulation of $\mathrm{K}_{2 \mathrm{P}} 3.1$ $\mathrm{K}^{+}$Current Causes Action Potential Shortening in Patients With Chronic Atrial Fibrillation". Circulation 2016;133:e440-441.

13 Dadi PK, Vierra NC, Jacobson DA: Pancreatic beta-cell-specific ablation of TASK-1 channels augments glucose-stimulated calcium entry and insulin secretion, improving glucose tolerance. Endocrinology 2014;155:3757-3768.

14 Shinoda K, Luijten IH, Hasegawa Y, Hong H, Sonne SB, Kim M, Xue R, Chondronikola M, Cypess AM, Tseng YH, Nedergaard J, Sidossis LS, Kajimura S: Genetic and functional characterization of clonally derived adult human brown adipocytes. Nat Med 2015;21:389-394.

15 Svensson PA, Jernas M, Sjoholm K, Hoffmann JM, Nilsson BE, Hansson M, Carlsson LM: Gene expression in human brown adipose tissue. Int J Mol Med 2011;27:227-232.

16 Russ U, Ringer T, Siemen D: A voltage-dependent and a voltage-independent potassium channel in brown adipocytes of the rat. Biochim Biophys Acta 1993;1153:249-256.

17 Nishizuka M, Hayashi T, Asano M, Osada S, Imagawa M: KCNK10, a tandem pore domain potassium channel, is a regulator of mitotic clonal expansion during the early stage of adipocyte differentiation. Int J Mol Sci 2014;15:22743-22756.

18 Locke AE, Kahali B, Berndt SI, Justice AE, Pers TH, Day FR, Powell C, Vedantam S, Buchkovich ML, Yang J, Croteau-Chonka DC, Esko T, Fall T, Ferreira T, Gustafsson S, Kutalik Z, Luan J, Magi R, Randall JC, Winkler TW, et al.: Genetic studies of body mass index yield new insights for obesity biology. Nature 2015;518:197206.

19 Pisani DF, Beranger GE, Corinus A, Giroud M, Ghandour RA, Altirriba J, Chambard JC, Mazure NM, Bendahhou S, Duranton C, Michiels JF, Frontini A, Rohner-Jeanrenaud F, Cinti S, Christian M, Barhanin J, Amri EZ: The $\mathrm{K}^{+}$channel TASK1 modulates beta-adrenergic response in brown adipose tissue through the mineralocorticoid receptor pathway. FASEB J 2016;30:909-922.

20 Li P, Pan F, Hao Y, Feng W, Song H, Zhu D: SGK1 is regulated by metabolic-related factors in 3T3-L1 adipocytes and overexpressed in the adipose tissue of subjects with obesity and diabetes. Diabetes Res Clin Pract 2013;102:35-42.

-21 Firestone GL, Giampaolo JR, O’Keeffe BA: Stimulus-dependent regulation of serum and glucocorticoid inducible protein kinase (SGK) transcription, subcellular localization and enzymatic activity. Cell Physiol Biochem 2003;13:1-12.

22 Webster MK, Goya L, Firestone GL: Immediate-early transcriptional regulation and rapid mRNA turnover of a putative serine/threonine protein kinase. J Biol Chem 1993;268:11482-11485.

23 Webster MK, Goya L, Ge Y, Maiyar AC, Firestone GL: Characterization of sgk, a novel member of the serine/ threonine protein kinase gene family which is transcriptionally induced by glucocorticoids and serum. Mol Cell Biol 1993;13:2031-2040.

24 Lang F, Bohmer C, Palmada M, Seebohm G, Strutz-Seebohm N, Vallon V: (Patho)physiological significance of the serum- and glucocorticoid-inducible kinase isoforms. Physiol Rev 2006;86:1151-1178.

25 Kobayashi T, Cohen P: Activation of serum- and glucocorticoid-regulated protein kinase by agonists that activate phosphatidylinositide 3-kinase is mediated by 3-phosphoinositide-dependent protein kinase-1 (PDK1) and PDK2. Biochem J 1999;339:319-328.

26 Liu P, Gan W, Chin YR, Ogura K, Guo J, Zhang J, Wang B, Blenis J, Cantley LC, Toker A, Su B, Wei W: PtdIns(3, 4,5)P3-Dependent Activation of the mTORC2 Kinase Complex. Cancer Discov 2015;5:1194-1209.

27 Lang F, Henke G, Embark HM, Waldegger S, Palmada M, Bohmer C, Vallon V: Regulation of channels by the serum and glucocorticoid-inducible kinase - implications for transport, excitability and cell proliferation. Cell Physiol Biochem 2003;13:41-50.

28 Lang F, Vallon V, Grahammer F, Palmada M, Bohmer C: Transport regulation by the serum- and glucocorticoid-inducible kinase SGK1. Biochem Soc Trans 2005;33:213-215.

29 Bhargava A, Pearce D: Mechanisms of mineralocorticoid action: determinants of receptor specificity and actions of regulated gene products. Trends Endocrinol Metab 2004;15:147-153. 


\section{Cellular Physiology Cell Physiol Biochem 2017;44:1024-1037 \begin{tabular}{l|l|l} 
and Biochemistry Published online: November 27, 2017 & $\begin{array}{l}\text { (c) } 2017 \text { The Author(s). Published by S. Karger AG, Basel } \\
\text { www.karger.com/cpb }\end{array}$
\end{tabular} \\ Rinné et al.: SGK and PKB Regulation of TASK-1/3}

-30 Fillon S, Warntges S, Matskevitch J, Moschen I, Setiawan I, Gamper N, Feng YX, Stegen C, Friedrich B, Waldegger S, Broer S, Wagner CA, Huber SM, Klingel K, Vereninov A, Lang F: Serum- and glucocorticoiddependent kinase, cell volume, and the regulation of epithelial transport. Comp Biochem Physiol A Mol Integr Physiol 2001;130:367-376.

-31 Pearce D: SGK1 regulation of epithelial sodium transport. Cell Physiol Biochem 2003;13:13-20.

-32 Stockand JD: New ideas about aldosterone signaling in epithelia. Am J Physiol Renal Physiol 2002;282:F559-576.

33 Verrey F, Loffing J, Zecevic M, Heitzmann D, Staub O: SGK1: aldosterone-induced relay of $\mathrm{Na}^{+}$transport regulation in distal kidney nephron cells. Cell Physiol Biochem 2003;13:21-28.

34 Yun CC: Concerted roles of SGK1 and the $\mathrm{Na}^{+} / \mathrm{H}^{+}$exchanger regulatory factor 2 (NHERF2) in regulation of NHE3. Cell Physiol Biochem 2003;13:29-40.

-35 Zuzarte M, Heusser K, Renigunta V, Schlichthörl G, Rinné S, Wischmeyer E, Daut J, Schwappach B, PreisigMüller R: Intracellular traffic of the $\mathrm{K}^{+}$channels TASK-1 and TASK-3: role of N- and C-terminal sorting signals and interaction with 14-3-3 proteins. J Physiol 2009;587:929-952.

-36 Sano H, Kane S, Sano E, Miinea CP, Asara JM, Lane WS, Garner CW, Lienhard GE: Insulin-stimulated phosphorylation of a Rab GTPase-activating protein regulates GLUT4 translocation. J Biol Chem 2003;278:14599-14602.

-37 Debonneville C, Flores SY, Kamynina E, Plant PJ, Tauxe C, Thomas MA, Munster C, Chraibi A, Pratt JH, Horisberger JD, Pearce D, Loffing J, Staub O: Phosphorylation of Nedd4-2 by Sgk1 regulates epithelial Na ${ }^{+}$ channel cell surface expression. EMBO J 2001;20:7052-7059.

-38 Snyder PM, Olson DR, Kabra R, Zhou R, Steines JC: cAMP and serum and glucocorticoid-inducible kinase (SGK) regulate the epithelial $\mathrm{Na}^{+}$channel through convergent phosphorylation of Nedd4-2. J Biol Chem 2004;279:45753-45758.

-39 Snyder PM, Olson DR, Thomas BC: Serum and glucocorticoid-regulated kinase modulates Nedd4-2mediated inhibition of the epithelial $\mathrm{Na}^{+}$channel. J Biol Chem 2002;277:5-8.

40 Embark HM, Bohmer C, Vallon V, Luft F, Lang F: Regulation of KCNE1-dependent $\mathrm{K}^{+}$current by the serum and glucocorticoid-inducible kinase (SGK) isoforms. Pflugers Arch 2003;445:601-606.

41 Palmada M, Embark HM, Yun C, Bohmer C, Lang F: Molecular requirements for the regulation of the renal outer medullary $\mathrm{K}^{+}$channel ROMK1 by the serum- and glucocorticoid-inducible kinase SGK1. Biochem Biophys Res Commun 2003;311:629-634.

42 Yun CC, Palmada M, Embark HM, Fedorenko O, Feng Y, Henke G, Setiawan I, Boehmer C, Weinman EJ, Sandrasagra S, Korbmacher C, Cohen P, Pearce D, Lang F: The serum and glucocorticoid-inducible kinase SGK1 and the $\mathrm{Na}^{+} / \mathrm{H}^{+}$exchange regulating factor NHERF2 synergize to stimulate the renal outer medullary $\mathrm{K}^{+}$channel ROMK1. J Am Soc Nephrol 2002;13:2823-2830.

43 Embark HM, Setiawan I, Poppendieck S, van de Graaf SF, Boehmer C, Palmada M, Wieder T, Gerstberger R, Cohen P, Yun CC, Bindels RJ, Lang F: Regulation of the epithelial $\mathrm{Ca}^{2+}$ channel TRPV5 by the NHE regulating factor NHERF2 and the serum and glucocorticoid inducible kinase isoforms SGK1 and SGK3 expressed in Xenopus oocytes. Cell Physiol Biochem 2004;14:203-212.

-44 Embark HM, Bohmer C, Palmada M, Rajamanickam J, Wyatt AW, Wallisch S, Capasso G, Waldegger P, Seyberth HW, Waldegger S, Lang F: Regulation of CLC-Ka/barttin by the ubiquitin ligase Nedd4-2 and the serum- and glucocorticoid-dependent kinases. Kidney Int 2004;66:1918-1925.

45 Sopjani M, Kunert A, Czarkowski K, Klaus F, Laufer J, Foller M, Lang F: Regulation of the $\mathrm{Ca}^{2+}$ channel TRPV6 by the kinases SGK1, PKB/Akt, and PIKfyve. J Membr Biol 2010;233:35-41.

46 Gehring EM, Lam RS, Siraskar G, Koutsouki E, Seebohm G, Ureche ON, Ureche L, Baltaev R, Tavare JM, Lang F: PIKfyve upregulates CFTR activity. Biochem Biophys Res Commun 2009;390:952-957.

47 Liang X, Butterworth MB, Peters KW, Frizzell RA: AS160 modulates aldosterone-stimulated epithelial sodium channel forward trafficking. Mol Biol Cell 2010;21:2024-2033.

48 Rajan S, Preisig-Müller R, Wischmeyer E, Nehring R, Hanley PJ, Renigunta V, Musset B, Schlichthörl G, Derst C, Karschin A, Daut J: Interaction with 14-3-3 proteins promotes functional expression of the potassium channels TASK-1 and TASK-3. J Physiol 2002;545:13-26.

-49 O’Kelly I, Butler MH, Zilberberg N, Goldstein SA: Forward transport. 14-3-3 binding overcomes retention in endoplasmic reticulum by dibasic signals. Cell 2002;111:577-588.

50 Ballou LM, Lin RZ, Cohen IS: Control of cardiac repolarization by phosphoinositide 3-kinase signaling to ion channels. Circ Res 2015;116:127-137. 